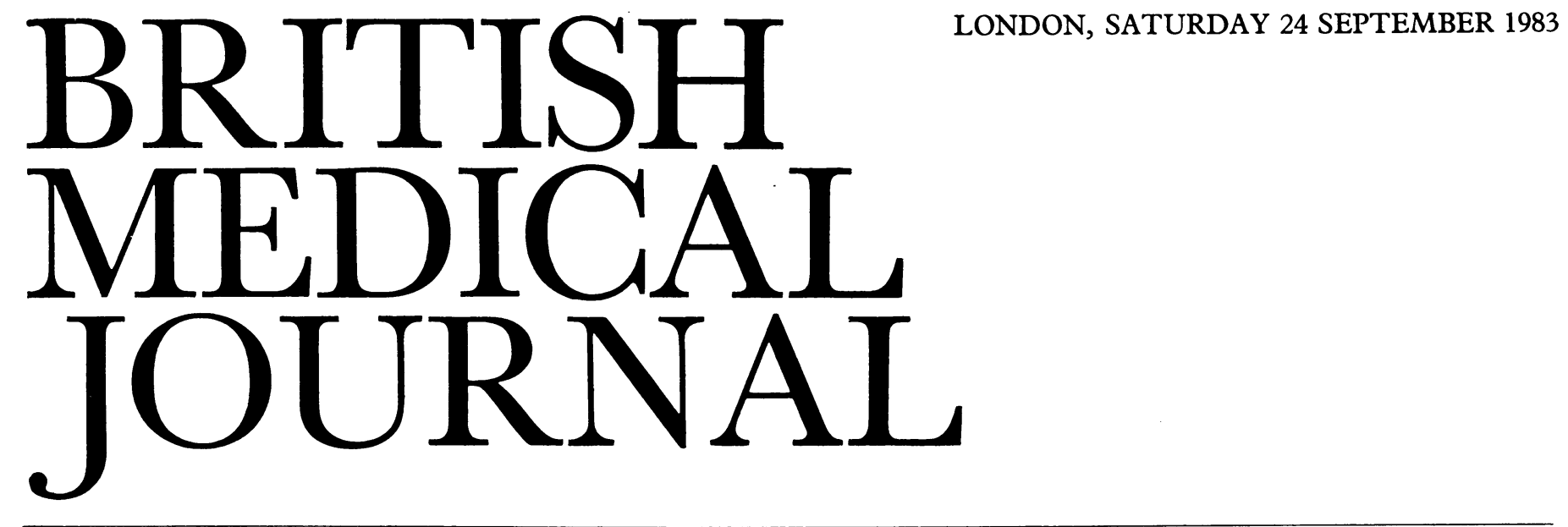

\title{
Captopril: five years on
}

The introduction of captopril - the first orally active inhibitor of angiotensin converting enzyme-into clinical medicine has been an example of skilled, purposeful pharmacological development; and the drug has been found to have a wider therapeutic range than might have been supposed initially. ${ }^{1-9}$

The small but distinct fall in blood pressure seen in normal people treated with captopril supported data from earlier studies suggesting that peripheral plasma concentrations of angiotensin II are within a pressor range. Captopril has been shown to be an effective antihypertensive agent in hypertension accompanying renovascular disease, and, when combined with loop diuretics, in previously intractable hypertension. As sole treatment in essential hypertension, its antihypertensive action is similar to that of beta-adrenoceptor blockers or thiazide diuretics; it appears particularly useful in essential hypertension when given together with a thiazide. ${ }^{10-12}$ Beneficial results of its administration have been seen also in severe cardiac failure and in crises of scleroderma.

Some, but not necessarily all, components of the drug's antihypertensive action come from a fall in circulating concentrations of angiotensin II. The extent of the drop in blood pressure after the initial dose is proportional to the concurrent reduction in plasma angiotensin II and to the pretreatment concentrations of renin and angiotensin II. With continued dosage a further fall in pressure often occurs which does not relate so closely, and in some studies not at all, to renin values before treatment. Some, but perhaps not every one, of the components of this slower fall in arterial pressure might be a late consequence of inhibition of angiotensin II formation, and thus of antagonism of the slow pressor effect of angiotensin II. Possibilities include diminution of sympathetic nervous activity; postsynaptic alpha adrenoceptor blockade; resetting of baroreceptors; increased renal blood flow; a fall in secretion of aldosterone; enhanced production of prostaglandins; prolonged survival of kinins in various tissues; and loss of sodium. A benefit (probably resulting from the usual fall in plasma concentrations of aldosterone) is that hypokalaemia induced by diuretics is unusual with concurrent administration of captopril.

The mechanisms controlling sodium retention, venoconstriction, and arterial constriction in congestive cardiac failure have not been fully clarified, though the renin-angiotensin system almost certainly plays an important part. Captopril induces a fall in arterial pressure with increased cardiac output, a fall in total peripheral resistance and right atrial pressure, improvement in the renal plasma flow, and a reduction in secretion of aldosterone. Nevertheless, though captopril produces a definite symptomatic and haemodynamic benefit, it has not yet been shown to prolong survival.

Captopril appears to be tolerated remarkably well in most patients. Indeed, those treated previously with complex antihypertensive regimens may comment spontaneously of an enhanced sense of wellbeing. Unfortunately the early dosage schedules recommended by the manufacturers were almost certainly too high. The molecule of captopril contains a sulphydryl group; moreover, the drug depends on the kidney for elimination. Toxic effects might, therefore, be expected to be dose related and to be more prominent in patients with impaired renal function.

Though there is no consensus that the toxic effects of captopril are related to the sulphydryl group, the pattern is similar to that seen with penicillamine, which also contains this group. Among the side effects reported are rashes, fever, arthralgia, disturbance of taste, Raynaud's phenomenon, aphthous ulcers, leucopenia, proteinuria, and the nephrotic syndrome-though a causal relation with the drug has not been established in all instances. For example, the report of two patients who developed neuropathy after treatment with captopril and cimetidine ${ }^{13}$ has not been followed by others, and neither captopril nor cimetidine, given separately or together, can readily be incriminated. In several of the instances of agranulocytosis the patients were receiving a complex drug regimen and had serious intercurrent disease. Recent evidence suggests that lowering the dosage of captopril to a maximum of $150 \mathrm{mg}$ daily from the originally recommended $450 \mathrm{mg}$ daily may help avoid the more serious, and perhaps also even the mild, side effects. ${ }^{10-12}{ }^{14-16}$ Dosage should be reduced further in patients with renal impairment.

Some of the specific effects (rather than side effects) of captopril demand caution. When the drug is given to patients with severe hypertension-who often will have been treated earlier with complicated therapeutic regimens-the fall in blood pressure may be steep and not always readily predictable. ${ }^{17}$ In such cases the drug should be given under close supervision, with facilities on hand for correction of hypotension by infusion of angiotensin II or by administration of saline if necessary. Captopril may also cause severe hypotension in patients with heart failure, but this is usually of less concern than in hypertension; for, unlike those with hypertension, patients with heart failure are not likely to have any upward resetting of the limits of autoregulation of cerebral blood flow. ${ }^{18}$ Dangerous hypotension is not probable with even large doses of captopril in normal people or in patients with mild hypertension. Rebound hypertension does not occur 
when the drug is stopped. The combination of captopril with large doses of loop diuretics in patients with impaired renal function can further raise serum concentrations of urea and creatinine. Hyperkalaemia is unusual but has been seen occasionally. One small double blind study found no evidence of a euphoriant effect of captopril ${ }^{19}$; such trials might usefully be extended and refined.

Some problems that had been expected with treatment with captopril have not materialised. For example, patients on long term dosage may attain very high circulating concentrations of angiotensin I and renin. Indeed, because renin substrate levels fall with captopril, measurements of plasma renin activity will underestimate the rise of renin concentration, ${ }^{20}$ and increases in circulating renin may be a good deal higher than appeared from some of the early reports. So far, however, no adverse effects attributable to angiotensin I or renin have been identified. Furthermore-at least with captopril $150 \mathrm{mg}$ three times daily-despite the very high resulting concentrations of renin and angiotensin I, no evidence has been found of any breakthrough of converting enzyme inhibition and consequent generation of angiotensin II or angiotensin III in the circulation. ${ }^{21}$

We believe that the introduction of orally active converting enzyme inhibitors has been a major advance in cardiovascular treatment. The past five years have seen a widening of their therapeutic range, but this has yet to be fully delineated. Problems associated with the use of these agents have been identified and substantially resolved. The next five years should see their potential exploited.

\section{G P HODSMAN \\ Medical registrar J I S ROBERTSON}

MRC Blood Pressure Unit,

Western Infirmary,

Glasgow G11 6NT

${ }^{1}$ Atkinson AB, Robertson JIS. Captopril in the treatment of clinical hypertension and cardiac failure. Lancet 1979;ii:836-9.

${ }^{2}$ Case DB, Sonnenblick EH, Laragh JH, eds. Captopril and hypertension. New York : Plenum Press, 1980.

${ }^{3}$ Brunner HR, Gross F, eds. Recent advances in hypertension therapy: captopril. Amsterdam: Excerpta Medica, 1981.

4 Heel RC, Brogden RN, Speight TM, Avery GS. Captopril: a preliminary review of its pharmacological properties and therapeutic efficacy. Drugs $1980 ; 20: 409-52$

${ }^{5}$ Horovitz ZP, ed. Angiotensin converting enzyme inhibitors: mechanisms of action and clinical implications. Baltimore: Urban and Schwartzenberg, 1980. (A N Richards Symposium).

${ }^{6}$ Zanchetti A, Tarazi RD, eds. Symposium on angiotensin-converting enzyme inhibition: a developing therapeutic concept. Am $\mathcal{F}$ Cardiol 1982;49:1381-579.

${ }^{7}$ Breckenridge A, ed. Captopril: worldwide clinical experience. $\mathrm{Br} \mathcal{F}$ Clin Pharmacol 1982;14 (suppl 2):65-252.

${ }^{8}$ Dargie HJ, Ball SG, Atkinson AB, Robertson JIS. Converting enzyme inhibitors in hypertension and heart failure. Br Heart $\mathcal{F} 1983$;49:305-8.

9 Vidt DG, Bravo EL, Fouad FM. Drug therapy: captopril. $N$ Engl 7 Med $1982 ; 306: 214-9$.

${ }^{10}$ Veterans Administration Cooperative Study Group on Antihypertensive Agents. Captopril: evaluation of low doses, twice-daily doses and the addition of diuretic for the treatment of mild to moderate hypertension. Clin Sci 1982;63 (suppl 8):443s-5s.

${ }^{11}$ Weinberger $\mathrm{MH}$. The influence of angiotensin converting enzyme inhibition on diuretic-induced metabolic effects. Abstracts, First European Meeting on Hypertension, Milan, May 1983.

${ }^{12}$ Weber MA, Drayer JIM, Alexander JC. Monotherapy with captopril in mild to moderate essential hypertension. Abstracts, First European Meeting on Hypertension, Milan, May 1983.

${ }^{13}$ Atkinson AB, Brown JJ, Lever AF, et al. Neurological dysfunction in two patients receiving captopril and cimetidine. Lancet 1980;ii:36-7.

${ }^{14}$ Smith SJ, Markandu ND, MacGregor GA. Optimal dose of captopril in hypertension. Lancet 1982 ;ii: 1460 .

${ }^{15}$ Isles GC, Hodsman GP, Robertson JIS. Side-effects of captopril. Lancet $1983 ; \mathrm{i}: 355$.

${ }_{16}^{16}$ Dombey S. Optimal dose of captopril in hypertension. Lancet 1983; i :529.

12 Hodsman GP, Isles CG, Murray GD, Usherwood TP, Webb DJ, Robertson JIS. Factors related to the first dose hypotensive effect of captopril: prediction and treatment. $\mathrm{Br}$ Med $\mathcal{F}$ 1983;286:832-4.
${ }^{18}$ Graham DI, Jones JV. Hypertension and the cerebral circulation with special reference to the pathophysiology of central nervous system complications of treatment. In : Robertson JIS, Pickering GW, Caldwell ADS, eds. The therapeutics of hypertension. New York: Academic Press, 1980:105-13. (Royal Society of Medicine. International Congress and Symposium Series. No 26.)

i9 Callender J, Hodsman GP, Robertson JIS. Mood changes during captopril therapy for hypertension: a double blind pilot study. Abstracts, First European Meeting on Hypertension, Milan, May, 1983.

20 Rasmussen S, Nielsen MD, Giese J. Captopril combined with thiazide lowers renin substrate concentration: implications for methodology in renin assays. Clin $S_{c i} 1981 ; 60: 591-3$.

${ }^{21}$ Atkinson AB, Cumming AMM, Brown JJ, et al. Captopril treatment: inter-dose variations in renin, angiotensins $I$ and II, aldosterone and blood pressure. Br $\mathcal{F}$ Clin Pharmacol 1982;13:855-8.

\section{Irritable bowel syndrome: still in search of its identity}

The irritable bowel syndrome accounts for a third to a half of referrals to gastroenterologists, ${ }^{1}$ yet remarkably little is understood of its pathogenesis. Anyone who looks after patients with the syndrome knows that they vary greatly, both in their symptoms and in their response to treatment. Indeed, experts are trying hard to identify subgroups with more constant symptom patterns and-they hope-a more predictable response to treatment.

This urge to subdivide and classify the irritable bowel syndrome dominated an international workshop on the disease held at Chateau Impney in June this year. One important step, made in 1962, was when Chaudhary and Truelove separated a group with painless diarrhoea from the majority who had pain and a variable bowel habit, the spastic colon group. ${ }^{2}$ Since then we have learned that pain may arise in the small intestine as well as the colon and that patients often have symptoms arising from the oesophagus and gastroduodenum. ${ }^{34}$ Hence most gastroenterologists now speak of the irritable bowel or even the irritable gut ${ }^{5}$ rather than of the irritable colon.

One of the problems in defining varieties of the irritable bowel syndrome is the lack of objective evidence of gut dysfunction in this condition. Patients with the irritable bowel syndrome who attend hospital have a high prevalence of neurotic traits and some regard them as merely oversensitive and overanxious people who notice and complain about normal abdominal sensations and about normal variations in bowel habit. This is unfair, since obvious spasm may sometimes be seen on barium radiographs (as well as on manometry), and the excess excretion of mucus is clear evidence of colonic malfunction, if not irritation. Nevertheless, patients with the irritable bowel syndrome are oversensitive to distension of the bowel, ${ }^{6}$ and they tend to make more of a fuss about minor ailments than other people. ${ }^{7}$

Classically the patient with the irritable bowel syndrome complains of alternating constipation and diarrhoea. This should be easy to document. What could be simpler than weighing the stools for several weeks and repeatedly measuring the passage time of radio-opaque pellets in a series of patients and then relating the findings to their symptoms? That would at least indicate how far the patients' bowel function varies from normal and whether it does indeed swing from constipation to diarrhoea and back again. Such a study has never been reported, and even in normal people the scanty data show that the function of the colon varies wildly, not only among individuals but even in the same normal person at 